\title{
The Mixture of Fatty Acids Conversion into Hydrocarbons Over Original $\mathrm{Pt}-\mathrm{Sn} / \mathrm{Al}_{2} \mathrm{O}_{3}$ Catalyst
}

\author{
A.E. Gekhman, A.V. Chistyakov, M.V. Tsodikov, P.A. Zharova, \\ S.S. Shapovalov and A.A. Pasynskii
}

\begin{abstract}
Development of alternative approaches to fuel components and basic organic synthesis precursors producing based on biomass treatment products is important objective for ecology and chemistry. In this work, a number of original $\mathrm{Pt}-\mathrm{Sn}$ containing catalysts were used for the mixture of fatty acids conversion. The peculiarities of used catalysts are usage of heterometallic precursors that possesses metal-metal bonds. Such kind of catalysts precursors allow obtaining more active and selective catalysts then ones based on a mixture of monometallic Pt and $\mathrm{Sn}$ precursors. Structural peculiarities of catalysts were characterized with TEM\&EDS and XAS technique. Relations between Pt clusters structure and its catalytic properties were determined.
\end{abstract}

Keywords Heterogeneous catalysis - Green diesel

A.E. Gekhman $(\bowtie) \cdot$ A.V. Chistyakov · M.V. Tsodikov · P.A. Zharova MIPT, Moskovskaya, Russia

e-mail: gekhman@mail.ru
A.V. Chistyakov
e-mail: chistyakov@ips.ac.ru
M.V. Tsodikov
e-mail: tsodikov@ips.ac.ru
P.A. Zharova
e-mail: zharova@ips.ac.ru

S.S. Shapovalov · A.A. Pasynskii

IGIC RAS, Moscow, Russia

e-mail: sshap@yandex.ru

\author{
A.A. Pasynskii \\ e-mail: pasynskii@igic.ras.ru \\ (C) The Author(s) 2018
}




\section{Introduction}

Nowadays, a significant interest has been concentrated on effective approaches related to renewable biomass conversion into fuels. Development of motor fuel production processes on the basis of promising types of plant oils is being a subject of intensive research nowadays [2]. Well known is the process of oils conversion towards aromatics over zeolite containing catalysts modified with $\mathrm{Pd}$ and $\mathrm{Zn}$ [1], $\mathrm{Ni}-\mathrm{Mo}$ or Ni-W [4] and Co [3]. But due to aromatics containing reduction in modern gasoline fuels this route loses its perspective. Fatty acids obtained from different oil crops and waste edible fats are prospective raw materials for biofuel production [2]. A special attention is given to the production of fatty acids from crops capable of growing on non-croplands such as microalgae. The purpose of this study is to develop the chemical basis of a breakthrough technology that will make the move to large-scale production of fuel components and basic petrochemical products from microalgae biomass. The present work proposes catalysts and process for the high-selectivity conversion of fatty acids into hydrocarbons.

\section{Experimental}

Hydrothermal hydrolysis of triglycerides of fatty acids was carried out in a flow reaction vessel (internal diameter $4 \mathrm{~mm}$, length $400 \mathrm{~mm}$ of the heated part) equipped with the dosing pump Gilson 305 (10 SC head), the back pressure controller at the reactor outlet, the condenser and the products receiver. Suspension of $10 \%$ rapeseed oil and 5\% microcrystalline cellulose in distilled water fed into the flow reactor. Fatty acids extracted from condensate with diethyl ether, fatty acid content was determined by chromatography according to [5].

In the range of $250-350{ }^{\circ} \mathrm{C}$ and $200-300$ atm triglycerides of rapeseed oil are converted to fatty acid mixture. The ratio between oleic acid and stearic is equal to the ratio between appropriate fragments in the rapeseed oil. This indicates that unsaturated fragments of fattyacids are stable under reaction condition. At temperatures below $300{ }^{\circ} \mathrm{C}$ precipitation of microcrystalline cellulose is observed in the reaction products.

The active components in Sn: Pt molar ratios of 1 and 5 were deposited on $\gamma$-Al2O3 by the impregnation method. The platinum loading on the catalysts was $0.4 \mathrm{wt} \%$. Heterometallic $\mathrm{Pt}-\mathrm{Sn}$ bond-containing complex precursor $(\mathrm{PPh} 4) 3[\mathrm{Pt}$ $(\mathrm{SnCl} 3) 5]$ obtained according to a unique procedure, were used as precursors for catalyst preparation of the [6].

Both gaseous and liquid organic products in aqueous and organic phases were identified by GC-MS. Catalyst testing was performed in a PID Eng and Tech microcatalytic fixed-bed flow reactor unit, equipped with relevant instrumentation and control devices, under pressure $50 \mathrm{~atm}$ of $\mathrm{H}_{2}$, temperature $400-480{ }^{\circ} \mathrm{C}$, and substrates space velocity in the range of $1.2 \mathrm{~h}^{-1}$. 
High-resolution transmission electron microscopy (HRTEM) (a JEOL JEM_2010 microscope with a grid resolution of $0.14 \mathrm{~nm}$ and an accelerating voltage of $200 \mathrm{kV}$ ), and energy-dispersive X-ray spectroscopy (EDS) (EDAX attachment to an EDAX microscope, X-ray microanalyzer with a semiconductor $\mathrm{Si}(\mathrm{Li})$ detector with a resolution of $\sim 130 \mathrm{eV}$ ) were used to study the morphology, structure, composition, and particle size distribution of the samples. To construct particle size distribution histograms, the data for 192-243 particles were statistically processed.

The local structure and charge state of platinum were studied by XAFS spectroscopy. The XANES and EXAFS X-ray absorption spectra were measured at the Structural Materials Science station of the Kurchatov Center for Synchrotron Radiation and Nanotechnology. The spectra were measured in the transmission mode using two ionization chambers filled with argon. A monoblock monochromator with a $\mathrm{Si}(111)$ cut was used for the monochromatization of a synchrotron radiation beam. To prepare a sample, catalyst powder was pressed into a pellet $1.5 \mathrm{~mm}$ thick in an atmosphere of $\mathrm{H}_{2}$ or Ar; the pellet was covered with a thin polymer film and transferred to the spectrometer under anaerobic conditions. For each particular sample, three to four independent measurements were performed to check the reproducibility of the results.

\section{Results and Discussion}

The objectives of the study included

- Development co-hydrolysis process of triglycerides and fatty acids polysaccharide shell microalgal biomass watered to recover a lipid component;

- Development of new catalysts based on polynuclear metal complexes;

- Development of heterogeneous catalytic processes of fatty acids conversion.

In during of hydrothermal hydrolysis of triglycerides of fatty acids dependence of the oil conversion on the contact time is S-shaped (Fig. 1). At contact times of more than 6 min the conversion of oil tends to a certain limit. This can be explained by a decrease, of the oil concentration in the reaction mixture. In the range of $0.5-$ 5 min the conversion of oil nonlinear increases, the second time derivative of the curve is positive. S-shaped form of the dependence cannot be explained by a formation during the reaction of strong acids (bases) capable to catalyze the hydrolysis, the $\mathrm{pH}$ of the initial suspension as product and do not differ. An unusual form of dependence might be related to the accumulation in the system of free fatty acids, which changes the properties of the fluid, for example, can increase the solubility of the oil or oil droplets fragmentation occur, and, consequently, accelerate mass transfer processes.

Over $\mathrm{Sn} / \mathrm{Al}_{2} \mathrm{O}_{3}$ catalyst under $400{ }^{\circ} \mathrm{C}$, VHSV $1,2 \mathrm{~h}^{-1}$ the mixture of fatty acids converts into alkanes and olefins $\mathrm{C}_{3}-\mathrm{C}_{17}$ fraction and aromatics. As shown in Fig. 2 
Fig. 1 The dependence of the conversion of rapeseed oil on contact time. $300 \mathrm{~atm}$, $300{ }^{\circ} \mathrm{C}$

Fig. 2 Composition of hydrocarbons obtained during the mixture of fatty acids conversion over $\mathrm{Sn} / \mathrm{Al}_{2} \mathrm{O}_{3}$ catalyst
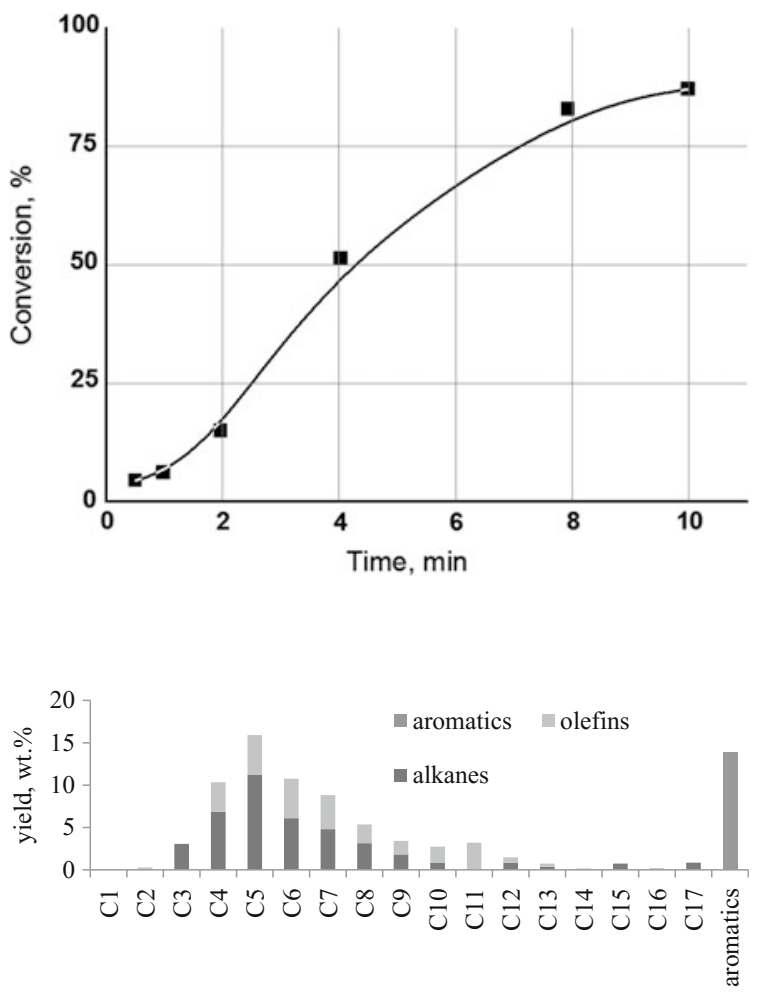

Fig. 3 Composition of hydrocarbons obtained during the mixture of fatty acids conversion over $1 \mathrm{Pt}-$ $5 \mathrm{Sn} / \mathrm{Al}_{2} \mathrm{O}_{3}$ catalyst

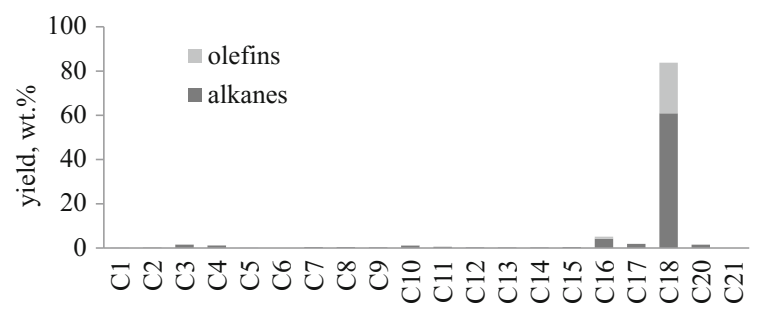

among aliphatic products hydrocarbons $\mathrm{C}_{4}-\mathrm{C}_{8}$ dominates that testify about intensive cracking of $\mathrm{C}-\mathrm{C}$ bond of fatty acids. Also considerable amount of aromatics was obtained. Its yield was $14 \mathrm{wt} \%$.

Comparison of products composition of the mixture of fatty acids conversion over $\mathrm{Pt}-\mathrm{Sn} / \mathrm{Al}_{2} \mathrm{O}_{3}$ catalysts showed that $\mathrm{Sn}$ content increasing led to intensification of $\mathrm{C}-\mathrm{O}$ bonds hydrogenation and reduction of cracking and decarboxylation processes. Over $1 \mathrm{Pt}-5 \mathrm{Sn} / \mathrm{Al}_{2} \mathrm{O}_{3}$ the highest yield of $\mathrm{C}_{3+}$ hydrocarbons was reached equal $99.5 \mathrm{wt} \%$ from which $84 \mathrm{wt} \%$ was $\mathrm{C}_{18}$ fraction and $4.5 \mathrm{wt} \% \mathrm{C}_{3}-\mathrm{C}_{4}$ fraction (Fig. 3). Among $\mathrm{C}_{18}$ fraction was found $23 \mathrm{wt} \%$ of olefins of which 7-10 wt $\%$ were linear alpha olefins. Obtained products may be used as $\mathrm{C}_{3}-\mathrm{C}_{4}$ fuel components 
extraction followed by disengagement of linear alpha olefins and the rest alkanes may be incorporated into high quality diesel fuel by hydroizomerization process. Should be noted that over $1 \mathrm{Pt}-5 \mathrm{Sn} / \mathrm{Al}_{2} \mathrm{O}_{3}$ catalyst take place mainly reduction of fatty acids into alkanes or olefins. Products of cracking and decarboxylation processes did not exceed $8 \mathrm{wt} \%$. Moreover, total yield of $\mathrm{C}_{1}$ products (methane, carbon oxides) observed lower then $0.1 \mathrm{wt} \%$.

Obtained XAS data (Figs. 4 and 5) showed that fine dispersion of Pt in initial and after experiment $1 \mathrm{Pt}-5 \mathrm{Sn} / \mathrm{Al}_{2} \mathrm{O}_{3}$ catalyst. In-depth quantitative analysis became more complicated due to absence of order in Pt envelope. In initial catalyst Pt has a wide range of near atoms $(\mathrm{O}, \mathrm{Cl}, \mathrm{Pt})$ with considerable differences in interatomic distances and coordination numbers. After catalytic experiments Pt reduction into $\mathrm{Pt}^{0}$ was observed but fine dispersion keep stable.

For the sample of $1 \mathrm{Pt}-5 \mathrm{Sn} / \mathrm{Al}_{2} \mathrm{O}_{3}$ catalyst obtained from the heterometallic complex the EDX data show that the quantity of $\mathrm{Sn}$ is close to $\sim 1$ at. $\%$ compared to Al. Particles of Pt are present in the form of clusters and small particles (marked with red circles) (Fig. 6). The sample of $1 \mathrm{Pt}-5 \mathrm{Sn} / \mathrm{Al}_{2} \mathrm{O}_{3}$ catalyst contains only two types of nanoparticles: Pt nanoparticles with a size of 1-2 nm, and ones with dimensions of $\sim 3-5 \mathrm{~nm}$ and of $\mathrm{PtSn}_{3 \pm \delta}$ composition, according to the EDS data. Note that the individual nanoparticles of "pure" tin were not found.

The results allow us to conclude that in the activated state the active ingredients consisting of superfine $\mathrm{Pt}, \mathrm{Sn} 2+, \mathrm{Sn} 4+$ particles and particles of $\mathrm{PtSn}_{3 \pm \delta}$ alloy are present on the surface of the catalyst system. Such a high selectivity of the catalyst in the conversion of the mixture of acids resulting in the quantitative yield of hydrocarbon fragments and water is probably caused by the chemisorption of the oxygen atoms of the carbonyl and ether groups on the ions of tin $\left(2^{+}-4^{+}\right)$.

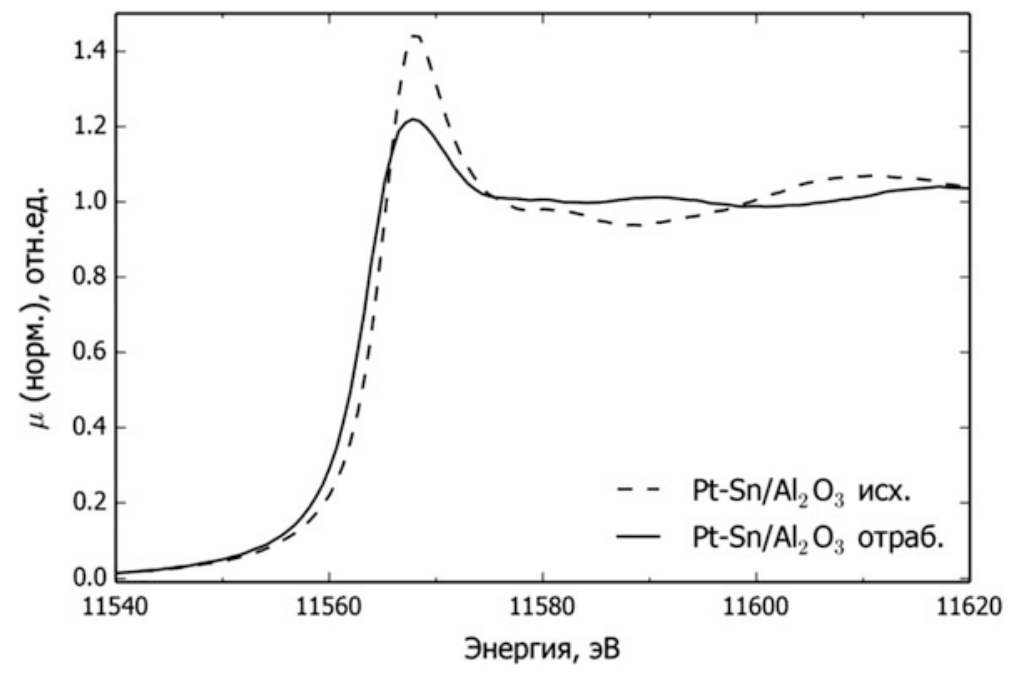

Fig. 4 XANES spectra for $1 \mathrm{Pt}-5 \mathrm{Sn} / \mathrm{Al}_{2} \mathrm{O}_{3}$ catalyst 


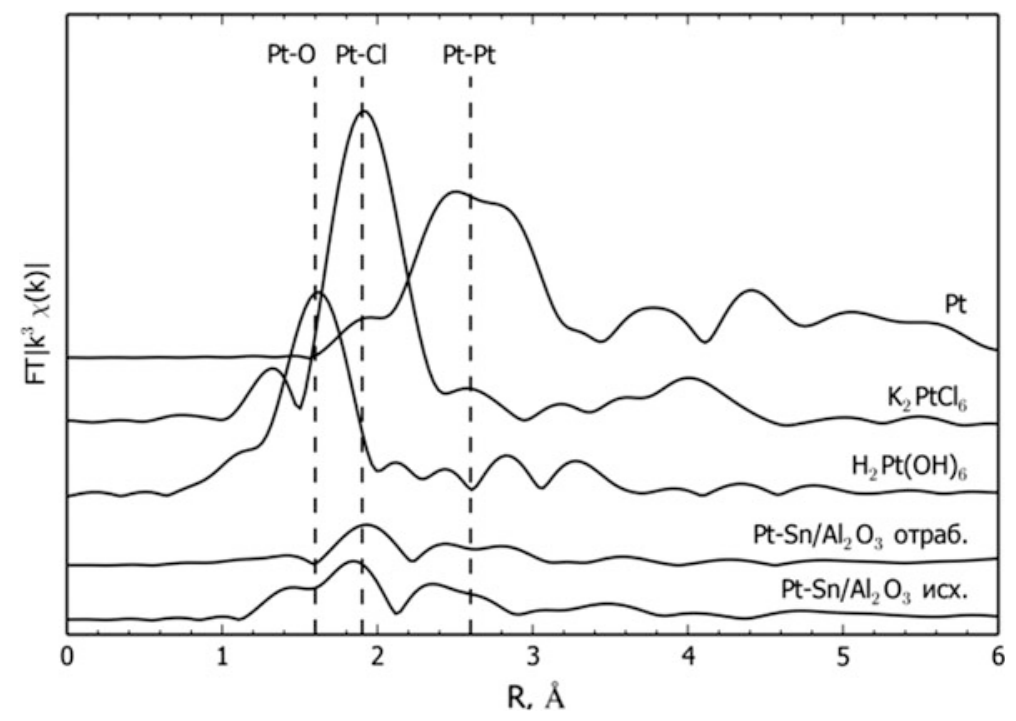

Fig. 5 EXAFS spectra for $1 \mathrm{Pt}-5 \mathrm{Sn} / \mathrm{Al}_{2} \mathrm{O}_{3}$ catalyst and a number of standards
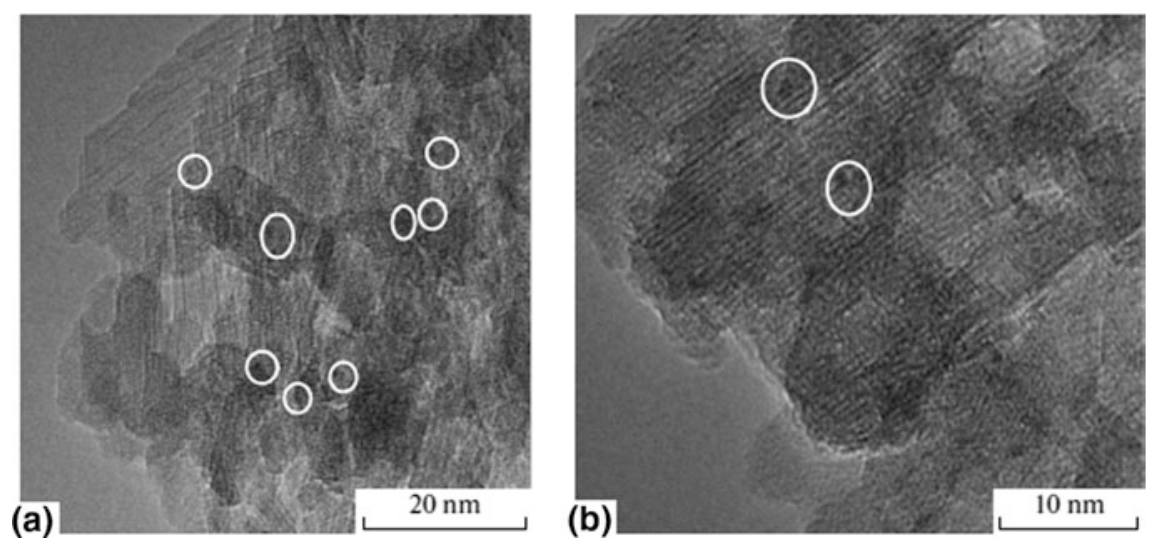

Fig. 6 TEM photomicrographs at different magnifications of a sample of the $1 \mathrm{Pt}-5 \mathrm{Sn} / \mathrm{Al}_{2} \mathrm{O}_{3}$ catalyst

\section{Conclusions}

Thus, in the presence of the $1 \mathrm{Pt}-5 \mathrm{Sn} / \mathrm{Al} 2 \mathrm{O} 3$ catalyst prepared by applying the heterometallic complex, highly selective conversion of the fatty acids mixture is achieved, resulting in the formation of only alkane-alkene hydrocarbons that are the same number of hydrocarbon atoms as in initial fatty acid; $\mathrm{C} 1$ byproducts formed as a result of cracking reactions and the removal of carbonyl and carboxyl groups of 
esters are nearly absent. That results in methane and carbon oxides formation suppression. Over $1 \mathrm{Pt}-5 \mathrm{Sn} / \mathrm{Al} 2 \mathrm{O} 3$ catalysts during conversion of the fatty acids mixture the $\mathrm{C}-\mathrm{O}$ hydrogenating selectivity significantly increases. During conversion of the fatty acids mixture under $400{ }^{\circ} \mathrm{C}$ a aliphatic hydrocarbons $\mathrm{C}_{3}-\mathrm{C}_{18}$ were obtained with total yield about $99 \%$ calculated on passed carbon. Noted that only two fractions of $\mathrm{C}_{3}$ and $\mathrm{C}_{18}$ hydrocarbons selectively formed. Obtained results allow minimizing loss of initial carbon weight due to cancelation of carboxyl fragment of fatty acids and glycerol conversion into methane and carbon oxides. Olefins $\mathrm{C}_{18}$ were found in products composition. Its yield was $23 \mathrm{wt} \%$ of which $7-10 \mathrm{wt} \%$ were linear alpha olefins. A high selectivity of the catalyst in the reaction of conversion of the fatty acids mixture is provided by two important factors: particle size factor and the structure of the precursor of the active ingredients. A small size of tin oxide and intermetallic alloy clusters probably set conditions for their interaction only with acid oxygen atoms as the most active centers of the substrate, but the clusters are spatially hindered for the reaction with unsaturated bonds in the carbon chain. The heterometallic complex used as a precursor of the active ingredients comprises a direct bond between the platinum and the tin atoms, which probably favors the formation on the surface of adjoining tin-containing and intermetallic centers having the ability for chemisorption of fatty acid by oxygen atoms, and for its reduction with hydrogen, and a weakened ability for cracking hydrocarbon fragments. This result made conversion of the fatty acids mixture over $1 \mathrm{Pt}-5 \mathrm{Sn} / \mathrm{Al}_{2} \mathrm{O}_{3}$ catalyst prospective for fuel components and monomers production.

Acknowlegments Researches are carried out with the financial support of the state represented by the Ministry of Education and Science of the Russian Federation. Agreement (contract) no. 14.575.21.0052. June 2014. Unique project Identifier: RFMEFI57514X0052.

\section{References}

1. Chistyakov A.V., Gubanov M.A., Tsodikov M.V.: The direct conversion of rapeseed oil towards hydrocarbons over industrial catalysts. Chem. Eng. Trans. 32, pp. 1093-1098 (2013)

2. Demirbas A.: Biodiesel: a realistic fuel alternative for diesel engines, p. 208. Springer-Verlad London Ltd., London (2008)

3. Kovács S., Boda L., Leveles L., Thernesz A., Hancsók J.: Catalytic hydrogenating of triglycerides for the production of bioparaffin mixture. Chem. Eng. Trans. 21, pp. 1321-1326 (2010)

4. Mikulec J., Cvengros J., Joríková L., Banic M., Kleinová A.: Diesel production technology from renewable sources - second generation biofuels. Chem. Eng. Trans. 18, pp. 475-480 (2009)

5. Nishiyama-Naruke A., Souza J.A., Carnelos M., Curi R.: HPLC determination of underivatized fatty acids saponified at 37C. Analysis of fatty acids in oils and tissues. Anal. Lett. 14, pp. 2565-2576 (1998)

6. Shapovalov S.S., Pasynskii A.A., Torubaev Yu.V., Skabitskii I.V., Scheer M., Bodensteiner M.: Stannylene complexes of manganese, iron, and platinum. Russ. J. Coord. Chem. 3, pp. 131-137 (2014) 
Open Access This chapter is licensed under the terms of the Creative Commons Attribution 4.0 International License (http://creativecommons.org/licenses/by/4.0/), which permits use, sharing, adaptation, distribution and reproduction in any medium or format, as long as you give appropriate credit to the original author(s) and the source, provide a link to the Creative Commons license and indicate if changes were made.

The images or other third party material in this chapter are included in the chapter's Creative Commons license, unless indicated otherwise in a credit line to the material. If material is not included in the chapter's Creative Commons license and your intended use is not permitted by statutory regulation or exceeds the permitted use, you will need to obtain permission directly from the copyright holder.

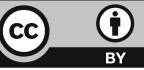

